\title{
ASSESSMENT OF DIETARY FIBER, ISOFLAVONES AND PHENOLIC COMPOUNDS WITH ANTIOXIDANT AND ANTIMICROBIAL PROPERTIES OF QUINOA (Chenopodium quinoa Willd.)
}

\author{
EVALUACIÓN DE FIBRA DIETÉTICA, ISOFLAVONAS Y \\ COMPUESTOS FENÓLICOS CON PROPIEDADES ANTIOXIDANTES Y \\ ANTIMICROBIANAS DE QUINOA (Chenopodium quinoa Willd.)
}

\begin{abstract}
Antonio Vega-Gálvez ${ }^{*}$, Liliana Zura', Mariane Lutz ${ }^{2}$, Rosa Jagus ${ }^{3,4}$, M. Victoria Agüero ${ }^{3,4}$, Alexis Pastén $^{1}$, Karina Di Scala ${ }^{4,5}$, Elsa Uribe ${ }^{1,6}$.
\end{abstract}

${ }^{1}$ Departamento de Ingeniería en Alimentos, Universidad de La Serena, Av. Raúl Bitran 1305, Box 599, La Serena, Chile.

${ }^{2}$ Centro de Investigación y Desarrollo de Alimentos Funcionales (CIDAF), Facultad de Farmacia, Universidad de Valparaíso, Gran Bretaña 1093, Valparaíso, Chile.

${ }^{3}$ Laboratorio de Microbiología Industrial, Departamento de Ingeniería Química, Facultad de Ingeniería, Universidad de Buenos Aires, Güiraldes 2160 - C1428EGA, Buenos Aires, Argentina.

${ }^{4}$ CONICET (Consejo Nacional de Investigaciones Científicas y Técnicas), Av. Rivadavia 1917 (C1033AAJ) CABA, Rivadavia, Argentina.

${ }^{5}$ Food Engineering Research Group, Universidad Nacional de Mar del Plata, Facultad de Ingeniería, Av. Juan B. Justo 4302. 7600, Mar del Plata, Argentina.

${ }^{6}$ Instituto de Investigación Multidisciplinar en Ciencia y Tecnología, Universidad de La Serena, Av. Raúl Bitrán 1305, La Serena, Chile

Autor para correspondencia E-mail: researcher.uls@gmail.com

\section{RESUMEN}

El consumo de quinua (Chenopodium quinoa Willd.) está aumentando debido a su valor nutricional y beneficios para la salud relacionados con su capacidad antioxidante. El objetivo de presente estudio fue determinar los contenidos de fibra dietética, polifenoles, flavonoides e isoflavonas, y cómo estos compuestos contribuyen a la actividad antioxidante y antimicrobiana de seis ecotipos de quinua cultivados en tres zonas de Chile. Las muestras de quinua de la zona Norte se denominan Ancovinto y Cancosa, de la zona Centro se llaman Cáhuil y Faro, y de la zona Sur se denominan Regalona y Villarrica. Los resultados mostraron que todos los ecotipos de quinua chilena

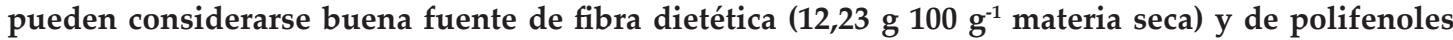
(161,32 mg de Equivalentes de Acido Gálico (EAG) $100 \mathrm{~g}^{-1}$ materia seca). Los ecotipos de la zona Norte y Centro mostraron la mayor concentración de isoflavonas. El ecotipo Cancosa, de la zona Norte, fue el que mostró el mayor contenido de flavonoides (211,06 mg Equivalentes de Catequina (ECA) $100 \mathrm{~g}^{-1}$ materia seca). Basado en el ensayo ORAC (del inglés Oxigen Radical Absorbance Capacity), los ecotipos Ancovinto, Cancosa y Faro, presentaron en promedio la mayor capacidad antioxidante (67,6 mmol de Equivalentes Trolox (ET) $100 \mathrm{~g}^{-1}$ materia seca). El ecotipo Regalona mostró la más alta actividad antimicrobiana frente a Saccharomyces cerevisiae y Listeria innocua. Los compuestos bioactivos encontrados en este estudio aportan nuevos conocimientos a la actividad antioxidante y antimicrobiana de las semillas de quinua chilena.

Palabras clave: ecotipos de quinoa, actividad antioxidante, isoflavonas, actividad antimicrobiana.

Received: 15 March 2017. Accepted: 29 September 2017 


\section{ABSTRACT}

The consumption of quinoa (Chenopodium quinoa Willd.) has been steadily increasing due to its high nutritional value and health benefits associated with its high antioxidant capacity. The objective of this study was to determine the contents of dietary fiber, polyphenols, flavonoids and isoflavones, and how they contribute to the antioxidant and antimicrobial activity of six ecotypes of quinoa cultivated in three different zones of Chile. The ecotypes studied were: Ancovinto and Cancosa (Northern zone), Cáhuil and Faro (Central zone), and Regalona and Villarrica (Southern zone). The results indicate that all Chilean quinoa ecotypes could be considered as good sources of dietary fiber (12.23 g $100 \mathrm{~g}^{-1}$ dry matter) and polyphenols (161.32 mg Gallic Acid Equivalents (GAE) $100 \mathrm{~g}^{-1}$ dry matter). The North and Central ecotypes exhibited the highest isoflavone concentration. The Northern Cancosa was the ecotype that showed the highest flavonoid content (211.06 $\mathrm{mg}$ Catechin Equivalents (CAE) $100 \mathrm{~g} \mathrm{~g}^{-1}$ dry matter). Based on the ORAC (Oxygen Radical Absorbance Capacity) assay, Ancovinto, Cancosa and Faro presented the highest antioxidant capacity $(67.6 \mathrm{mmol}$ Trolox Equivalents (TE) $100 \mathrm{~g} \mathrm{~g}^{-1}$ dry matter). Regarding antimicrobial activity, Regalona ecotype showed the best performance against Saccharomyces cerevisiae and Listeria innocua. The bioactive compounds found in this study add new knowledge to the antioxidant and antimicrobial activity of Chilean quinoa seeds.

Key words: Quinoa ecotypes, antioxidant activity, isoflavone, antimicrobial activity.

\section{INTRODUCTION}

Quinoa (Chenopodium quinoa Willd.) is a pseudocereal and an Andean native plant whose seeds are resistant to adverse environmental conditions, such as drought, hail and frost (Navruz-Varli and Sanlier, 2016). In fact, it is one of the few crops that grow on highly saline soil in Southern Bolivia and Northern Chile (Nowak et al., 2016). Since ancient times, quinoa has been appreciated by its nutritional value all over the world due to the exceptional balance among oil, protein and fat contents compared to cereals (Miranda et al., 2010). Besides, it has a high content of dietary fibers, which can have a favorable function in the colon and facilitate the absorption process of the other nutrients present in quinoa (Lamothe et al., 2015; Maradini Filho et al., 2015). Beyond its basic nutritional function of supplying nutrients, quinoa also has healthpromoting and/or disease-preventing properties (Tang et al., 2015; Navruz-Varli and Sanlier, 2016). The latter are associated with its high content of bioactive compounds of hydrophilic nature, such as phenolic acids and flavonoids (Miranda et al., 2010; Abderrahim et al., 2015; Tang et al., 2015), as well as isoflavones (daidzein and genistein) (Lutz et al., 2013) and betacyanidins (betanin and isobetanin) in colored quinoa seeds (Abderrahim et al., 2015; Tang et al., 2015). All these compounds are primarily responsible for both its antioxidant (Miranda et al., 2010; Abderrahim et al., 2015; Tang et al., 2015) and antimicrobial activity (Miranda et al., 2014).

Previous studies have described that quinoa seeds are an exceptionally rich source of phenolic acids, such as vanillic acid and ferulic acid and their derivatives, as well as flavonols, such as quercetin and kaempferol and their glycosides, in either free, bound or conjugated form (Dini et al., 2004; Hirose et al., 2010; Tang et al., 2015). These compounds are known for preventing many degenerative diseases, such as coronary heart disease, atherosclerosis, cancers, diabetes, and Alzheimer's disease, through antioxidative action and/or the modulation of several protein functions (Hirose et al., 2010; Navruz-Varli and Sanlier, 2016).

The objective of this study was to determine the proximate composition, dietary fiber, polyphenol, flavonoid and isoflavone contents as well as the antioxidant and antimicrobial capacity of six ecotypes of quinoa cultivated in three production zones of Chile

\section{MATERIALS AND METHODS}

\section{Raw material and sample preparation}

Quinoa seeds were harvested from three production areas of Chile: North Highlands, Central and Southern Chile. A total of 6 ecotypes of quinoa were used (one batch of $50 \mathrm{~kg}$ for each ecotype), including two per production area: Ancovinto and Cancosa (around 19ㅇ S) from the northern zone; Cáhuil and Faro (around $34^{\circ}$ S) from the central zone; and Regalona (official variety) and Villarrica (around $39^{\circ}$ S) from the southern zone. The samples were analyzed without unhusking, and then visually inspected to discard contaminant particles or impurities.

Determination of proximate composition and dietary fiber

The moisture content (AOAC $\mathrm{N}^{\circ}$ 934.06), 
crude proteins (AOAC $\mathrm{N}^{\circ}$ 960.52), fat (AOAC $\mathrm{N}^{\circ}$ 960.39), crude fiber (AOAC $\mathrm{N}^{\circ}$ 962.09) and crude ash (AOAC $\mathrm{N}^{\circ}$ 923.03) were determined according to AOAC methods (1990). The total carbohydrates were calculated by difference. Quinoa seed samples were analyzed for soluble and insoluble dietary fiber fractions according to a gravimetric enzymatic method (AOAC $\mathrm{N}^{\circ}$ 991.43) by using a Total Dietary Fiber Assay Kit (TDF100A, Sigma-Aldrich, St. Louis, Missouri, USA) by an Enzymatic Digestion Unit and a Filtration System (VELP Scientifica, GDE - CSF6, Usmate, Italy). Total dietary fiber was calculated as the sum of soluble and insoluble dietary fiber, and expressed as g $100 \mathrm{~g}^{-1}$ dry matter (d.m.). All measurements were performed in triplicate.

\section{Free and bound phenolic compounds: extraction procedure}

Dried quinoa seeds were milled using a basic analytical mill (IKA ${ }^{\circledR} \mathrm{A}-11$, Wilmington, Delaware, USA) and sieved with a stainless steel sieve \#35 of $500 \mu \mathrm{m}$ mesh (U.S. Standard Sieve Series, Dual Manufacturing Co., Chicago, ILL, USA). Five grams were accurately weighed and transferred into an Erlenmeyer flask and mixed with $20 \mathrm{~mL}$ acetone/water solution (4:1) on an orbital shaker (Boeco, OS20, Hamburg, Germany) for $60 \mathrm{~min}$ at $150 \mathrm{rpm}$ (room temperature). The mixture was centrifuged at $5000 \mathrm{rpm}$ for $3 \mathrm{~min}$ (Eppendorf centrifuge 5804R, Hamburg, Germany). The supernatant was collected, and the residue reextracted once more. The combined supernatant was evaporated by a rotary evaporator (Büchi R-210, Flawil, Switzerland) under a reduced pressure at $37^{\circ} \mathrm{C}$ and the residue was dissolved in $5 \mathrm{~mL}$ methanol-formic acid (99:1). The phenolic compounds (PC) obtained by this procedure were identified as 'free PC'.

Extraction of 'bound $\mathrm{PC}^{\prime}$ was carried out after the extraction of free PC. The free fraction residue was hydrolyzed with $20 \mathrm{~mL}$ of $2 \mathrm{M} \mathrm{NaOH}$ and agitated in an orbital shaker (Boeco, OS20, Hamburg, Germany) at $250 \mathrm{rpm}$ overnight at room temperature. The alkaline hydrolysate was acidified to $\mathrm{pH} 2$ with $4 \mathrm{M} \mathrm{HCl}$. The liberated bound fraction in the clear solution was extracted three times with $10 \mathrm{~mL}$ ethyl acetate. The pooled ethyl acetate extracts were evaporated to dryness under a reduced pressure in a rotary evaporator at $37^{\circ} \mathrm{C}$. The dried residue was dissolved in $5 \mathrm{~mL}$ methanol-formic acid (99:1). For all extraction steps, the extracts were protected from light by covering them with aluminum foil. Aliquots of all extracts were stored at $-80^{\circ} \mathrm{C}$ until analysis.

\section{Quantification of phenolic compounds by spectrophotometry}

Phenolic compounds (PC) were determined colorimetrically by using a Folin-Ciocalteau (FC) reagent in both fractions (free PC and bound PC) according to Chuah et al. (2008), and in agreement with the modifications described by Miranda et al. (2010). Absorbance was read at 725 $\mathrm{nm}$ using a spectrophotometer (Spectronic ${ }^{\circledR} 20$ GenesysTM131, Illinois, USA) and compared to a previously prepared gallic acid calibration curve $\left(y=0.0037 x-0.0071 ; r^{2}=0.9977\right)$. The results were expressed as Gallic Acid Equivalents per $100 \mathrm{~g}$ dry matter (mg GAE $100 \mathrm{~g}^{-1}$ d.m.). All reagents were purchased from Merck (Merck KGaA, Darmstadt, Germany).

\section{Total flavonoid content (TFC): extraction procedure}

Flavonoids from the quinoa samples were extracted as described by Kim et al. (2003) with some modifications. Briefly, quinoa seeds were milled and sieved as indicated above. Five grams were accurately weighed and shaken in $20 \mathrm{~mL}$ of $80 \%$ aqueous methanol. The mixture was agitated on an orbital shaker (Boeco, OS20, Hamburg, Germany) for $60 \mathrm{~min}$ at $200 \mathrm{rpm}$ (room temperature), then centrifuged at $5000 \mathrm{rpm}$ for 3 min (Eppendorf centrifuge 5804R, Hamburg, Germany). The supernatant was collected, and the residue re-extracted once more. The combined supernatant was evaporated by a rotary evaporator (Büchi R-210, Flawil, Switzerland) under a reduced pressure at $37^{\circ} \mathrm{C}$, and the residue was dissolved in $10 \mathrm{~mL}$ of $80 \%$ aqueous methanol.

\section{Quantification of Total Flavonoid Content (TFC) by spectrophotometry}

TFC was assessed by a colorimetric assay adapted from Miranda et al. (2014). Briefly, 0.1 $\mathrm{mL}$ aliquot of methanolic extract was mixed with $2.4 \mathrm{~mL}$ deionized water in a $5 \mathrm{~mL}$ microcentrifuge tube; a volume of $0.15 \mathrm{~mL} \mathrm{NaNO}_{2}\left(50 \mathrm{mg} \mathrm{mL}^{-1}\right)$ was then added, and allowed to react for $5 \mathrm{~min}$. Thereafter, $0.15 \mathrm{~mL} \mathrm{AlCl}_{3}\left(100 \mathrm{mg} \mathrm{mL}^{-1}\right)$ was added and the mixture was again allowed to stand for 6 min. Finally, volumes of $1.0 \mathrm{~mL} 1 \mathrm{M} \mathrm{NaOH}$ and $1.2 \mathrm{~mL}$ deionized water were added to the reaction mixture, and the absorbance at $510 \mathrm{~nm}$ was read against a blank by replacing the extract with deionized water. The TFC was calculated from a calibration curve using catechin as a standard (y $\left.=0.0086 x-0.0145 ; r^{2}=0.9969\right)$. The results were expressed as $\mathrm{mg}$ Catechin Equivalents per $100 \mathrm{~g}$ d.m. (mg CAE $100 \mathrm{~g}^{-1}$ d.m.). Samples and standards were determined in triplicate.

\section{Identification of isoflavones by high-performance liquid chromatography (HPLC) \\ Isoflavones (daidzein and genistein) in}


quinoa seeds were extracted using the method of Lutz et al. (2013). The quinoa extracts were analyzed by reversed-phase high-performance liquid chromatography (RP-HPLC, MerckHitachi, Frankfurt-Tokyo, Germany-Japan) using a Lichrosorb RP-18 column $(250 \mathrm{~mm} \times 4.0$ $\mathrm{mm}, 10 \mu \mathrm{m})$ according to the method of Lutz et al. (2013). The identification of the isoflavones (daidzein and genistein) was based on matching retention time with the respective standards. The calibration curves of the analyzed isoflavones were made in triplicate for each standard and plotted separately at concentrations in the range of $0.25-20.0 \mathrm{mg} \mathrm{mL}^{-1}$ for daidzein, and $0.28-22.4$ $\mathrm{mg} \mathrm{mL} \mathrm{m}^{-1}$ for genistein (Sigma Chemical Co., St. Louis, Missouri, USA).

Determination of antioxidant activity by the 22,-diphenyl-2-picryl-hydrazyl (DPPH) and Oxygen Radical Absorbance Capacity (ORAC) assays

The antioxidant activity of the methanolic extract was evaluated by 2,2,-diphenyl-2-picrylhydrazyl (DPPH) method (Uribe et al., 2016). Absorbance was read at $517 \mathrm{~nm}$ and antioxidant activity measured from a Trolox calibration curve with concentrations from 0.05 to $1.0 \mathrm{mM}$ ( $\mathrm{y}=-$ $\left.0.5198 x+0.5079 ; r^{2}=0.9956\right)$.

Extraction (Ou et al., 2002) and analysis (Zhang et al., 2010) of antioxidant activity by the Oxygen Radical Absorbance Capacity (ORAC) assay were carried out according to the modifications described by Uribe et al. (2016) in a Victor $\chi 3$ Multilabel Plate Reader (PerkinElmer, Turku, Finland). Fluorescence 240 was read every $60 \mathrm{~s}$ with an excitation wavelength $485 \mathrm{~nm}$ and an emission filter of $535 \mathrm{~nm}$ until fluorescence readings had declined to less than $5 \%$ of the initial value. Inhibition capacity was expressed as Trolox Equivalents and quantified by the difference between sample and blank areas under the kinetic fluorescein decay curve and a calibration curve $\left(\mathrm{y}=0.0002 \mathrm{x}-21.9511 ; \mathrm{r}^{2}\right.$ $=0.9729)$. The results of antioxidant activity were expressed as mmol Trolox Equivalent (TE) per $100 \mathrm{~g}$ d.m. (mmol TE $100 \mathrm{~g}^{-1}$ d.m.). Samples and standards were determined in triplicate.

\section{Microbiological assays}

Quinoa suspensions were prepared in a broth $\left(1 \mathrm{~g} 10 \mathrm{~mL}^{-1}\right)$ for each quinoa ecotype (full suspension). For this purpose, $2 \mathrm{~g}$ of quinoa were added to $20 \mathrm{~mL}$ of aqueous broth and agitated during $10 \mathrm{~min}$. Supernatants were obtained after centrifugation of these suspensions at 10,000 rpm during $10 \mathrm{~min}$ (Refrigerated centrifuge $5804 \mathrm{R}$, Eppendorf, Germany). Antimicrobial activity was evaluated by using the supernatants for all quinoa ecotypes and the full suspensions of Ancovinto and Villarrica ecotypes in order to determine the hydro-solubility of antimicrobial compounds. Sample coding is as follows: Control (broth without quinoa), Quinoa 1 (Ancovinto, full suspension), Quinoa 2 (Villarrica, full suspension), Quinoa 3 (Ancovinto, supernatant), Quinoa 4 (Villarrica, supernatant), Quinoa 5 (Cancosa, supernatant), Quinoa 6 (Regalona, supernatant), Quinoa 7 (Faro, supernatant) and Quinoa 8 (Cáhuil, supernatant).

\section{Strains and growth conditions}

Listeria innocua was used as a biological indicator for Listeria monocytogenes due to its similar response to physical, chemical or thermal treatments. L. innocua (CIP 8011, CCMA 29, Facultad de Farmacia y Bioquímica, Buenos Aires, Argentina) was grown in $200 \mathrm{~mL}$ each of Tryptic Soy broth enriched with $0.6 \%$ yeast extract (TSBYE, Biokar Diagnostics, France), in a continuously agitated temperature-controlled shaker at $28^{\circ} \mathrm{C}$ overnight. A volume of two $\mathrm{mL}$ of the culture was inoculated in $100 \mathrm{~mL}$ of fresh TSBYE, and agitated for approximately $1 \mathrm{~h}$ to obtain the desired final concentration of cells determined by optical density. Saccharomyces cerevisiae (CBS 1171, strain collection SC) was grown in $150 \mathrm{~mL}$ Sabouraud broth (Biokar Diagnostics, France) at $28^{\circ} \mathrm{C}$ in a continuously agitated temperature-controlled shaker until early stationary phase was achieved. In both cases, the cultures were centrifuged at 10,000 rpm for 20 and $10 \mathrm{~min}$ for bacteria and yeast, respectively. After the supernatants were removed, the pellets were re-suspended in quinoa suspensions (full suspension or supernatant) or in broth (for control). These systems were incubated at $25^{\circ} \mathrm{C}$ and samples were taken at $0,24,48,72$ and 144 $\mathrm{h}$ of storage. To determine the viable population of microorganisms, samples were serially diluted with a peptone water solution. Microbial counts were then made on plates of Oxford (Biokar Diagnostics, France) for L. innocua, and Chloramphenicol Glucose Agar (YGC, Biokar Diagnostics, France), for S. cerevisiae. The number of colony-forming unit (CFU) $\mathrm{mL}^{-1}$ was determined after incubation at $37^{\circ} \mathrm{C}$ and $28^{\circ} \mathrm{C}$ for $48 \mathrm{~h}$ and $72 \mathrm{~h}$, respectively. Determinations were made in duplicate in two separate experimental runs.

\section{Statistical analysis}

A one-way analysis of variance (ANOVA) was performed using Statgraphics Centurion XVI (Statistical Graphics Corp., Herdon, USA) to determine significant differences among the different quinoa ecotypes. Differences between 
the media were analyzed by using the least significant difference (LSD) test with a significance level of $\alpha=0.05$ and a confidence interval of $95 \%$ (p $<0.05$ ). In addition, the multiple range test (MRT) included in the statistical program was used to demonstrate the existence of homogeneous groups within each of the parameters.

\section{RESULTS AND DISCUSSION}

\section{Proximate composition analyses and dietary fiber}

The proximate composition analyses and dietary fiber content of the six quinoa ecotypes from the three zones of Chile (North, Central and South) are presented in Table 1 . As expected, the northern ecotypes presented lower moisture content (8.47-9.65 g $100 \mathrm{~g} \mathrm{~g}^{-1}$ ) compared to the values observed in the samples from the central

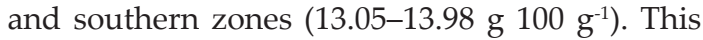
might be explained by the extremely dry climatic conditions in northern Chile, with rainfall fluctuating between 100 and $200 \mathrm{~mm} \mathrm{year}^{-1}$, while values in the central and southern zones of Chile fluctuate between 500 and $2000 \mathrm{~mm}_{\text {year }}^{-1}$ (Martínez et al., 2015).

The fat content of quinoa seeds of the six ecotypes studied ranged from 5.41 to $7.01 \mathrm{~g} 100$ $\mathrm{g}^{-1}$ of fat, while the ash content ranged from 3.08

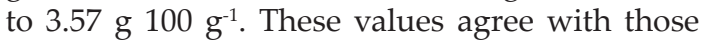
recently reported by Nowak et al. (2016) in quinoa cultivated in South America, Europe, Asia and Northern America.

Villarrica ecotype showed the highest protein content (16.24 g $\left.100 \mathrm{~g}^{-1}\right)$, which was 32\% higher

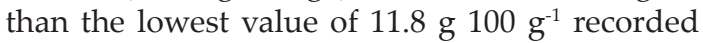
by the Cahuil ecotype, which is probably due to a high nitrogen bioavailability in volcanic soils of southern Chile (Huygens et al., 2008). Nowak et al. (2016) have reported that protein content of quinoa seeds varies between $9.1 \%$ and $15.7 \%$ with an average $13.1 \%$ d.m., while other studies have reported an average value of $15 \%$ d.m. (Maradini Filho et al., 2015; Navruz-Varli and Sanlier, 2016). These values are higher compared to the one found in rice, barley, corn, rye, and sorghum, or even wheat (Maradini Filho et al., 2015; NavruzVarli and Sanlier, 2016).

Regarding total carbohydrates, significant differences $(\mathrm{P}<0.05)$ were found between the six quinoa ecotypes. The levels observed in this

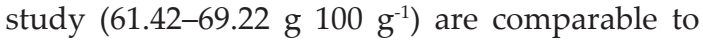
those reported by Repo-Carrasco-Valencia and Serna (2011) in four varieties of Peruvian quinoa (68.84-75.82 g $100 \mathrm{~g}^{-1}$ ). Regarding crude fiber, Ancovinto showed the lowest content with a

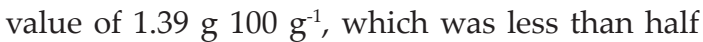
of the highest value recorded by Villarrica (3.04

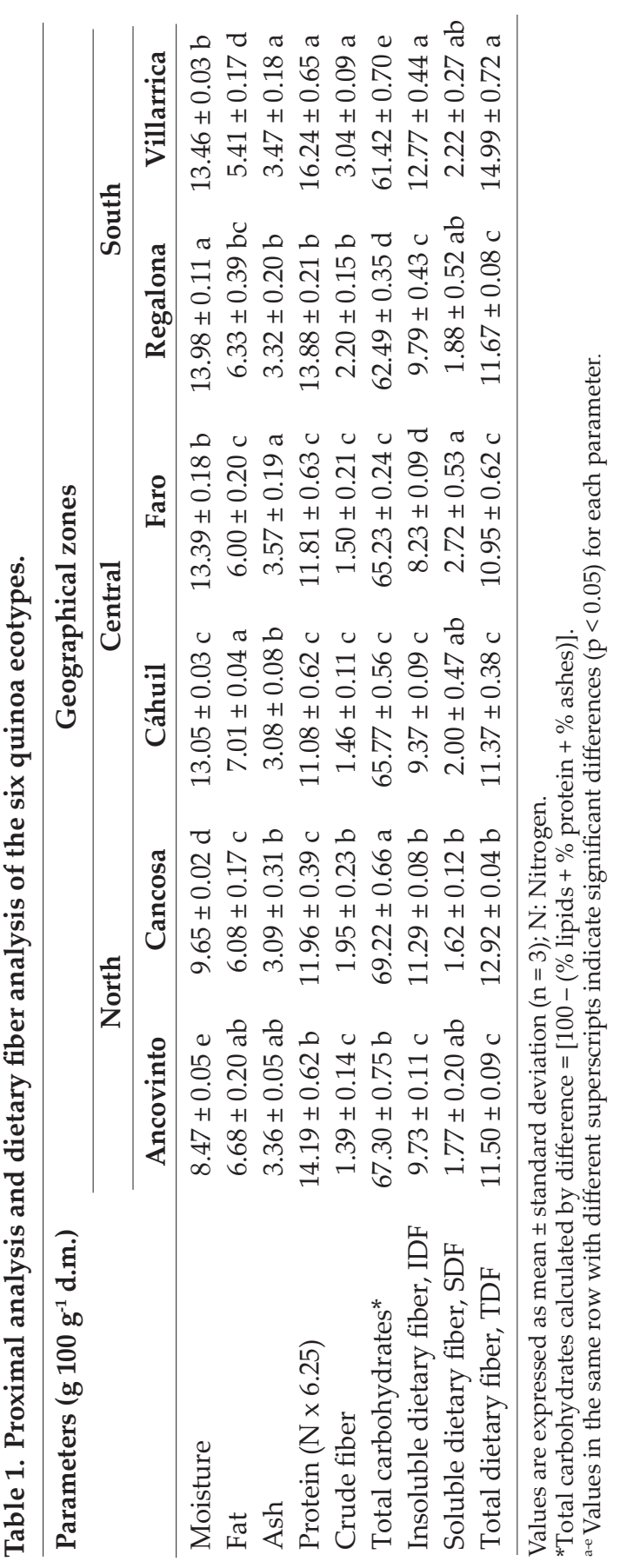

$\mathrm{g} 100 \mathrm{~g} \mathrm{~g}^{-1}$ ). On the other hand, total dietary fiber

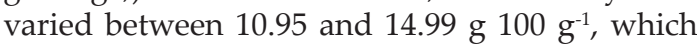
agrees with the values obtained by other authors (Repo-Carrasco-Valencia and Serna, 2011; Nowak et al., 2016). On average, the crude fiber of the six ecotypes (1.92 $\mathrm{g} 100 \mathrm{~g} \mathrm{~g}^{-1} \mathrm{~d}$.m.) accounted for only $16 \%$ of the dietary fiber content $\left(12.23 \mathrm{~g}^{100 \mathrm{~g}^{-1}}\right.$ d.m.). Therefore, crude fiber was significantly 
lower than total dietary fiber. The fact that quinoa dietary fiber includes more fiber fractions, such as xyloglucans and pectic polysaccharides in varying amounts, may account for this situation (Lamothe et al., 2015). The same authors have indicated that the composition of fiber in quinoa is different from that of cereals. In fact, fiber fractions from quinoa more closely resemble those of fruits, vegetables and leguminous seeds, providing good potential for a favorable function in the colon.

Free, bound and total phenolic compounds of Chilean quinoa seeds

The PC values of free and bound phenolic fractions of quinoa seeds were measured by the Folin-Ciocalteu method (Fig. 1). The PC values measured in the free phenolic fractions were higher than those in the bound fractions. The six Chilean quinoa ecotypes showed free PC values ranging from 97 to $164 \mathrm{mg}$ Gallic Acid Equivalents (GAE) $100 \mathrm{~g}^{-1}(\mathrm{p}<0.05)$. The highest free PC was observed in Faro (164 mg GAE $100 \mathrm{~g}^{-1}$ ), followed by Cáhuil (161 mg GAE $100 \mathrm{~g}^{-1}$ ). The results are in agreement with those reported by Tang et al. (2015) for white quinoa ( $220 \mathrm{mg}$ GAE $100 \mathrm{~g} \mathrm{~g}^{-1}$ ) cultivated in Ontario (Canada). Moreover, the bound PC ranged between 16 and $53 \mathrm{mg}$ GAE $100 \mathrm{~g} \mathrm{~g}^{-1}$; the highest values were observed in Villarrica (53 mg
GAE $\left.100 \mathrm{~g}^{-1}\right)(\mathrm{p}<0.05)$, followed by Cáhuil $(33 \mathrm{mg}$ GAE $100 \mathrm{~g}^{-1}$ ) and Ancovinto (32 mg GAE $100 \mathrm{~g} \mathrm{~g}^{-1}$ ) $(p>0.05)$. Finally, the total PC ranged from 112 and $194 \mathrm{mg} \mathrm{GAE} 100 \mathrm{~g}^{-1}(\mathrm{p}<0.05)$, with values that were significantly higher in Cáhuil (194 mg GAE $\left.100 \mathrm{~g}^{-1}\right)$ and Faro (187 mg GAE $\left.100 \mathrm{~g} \mathrm{~g}^{-1}\right)$, compared to the other ecotypes. These results show that the PC of quinoa seeds was approximately 2 -fold or 7-fold higher in the free form compared to the bound one. On the contrary, Abderrahim et al. (2015) determined a higher content of bound PC compared to free PC in thirteen colored quinoa seeds from the Peruvian Altiplano. Therefore, PC appears to be specific for each ecotype (groups of cultivars defined according to distributional, ecological, agronomic and morphological criteria) (Abderrahim et al., 2015).

In this sense, previous studies have described that the distribution of phenols in cereals and pseudo-cereals at the cellular and subcellular levels is not uniform. Bound phenols are found attached to cell wall structures, while free phenols are present in the outer layer of the pericarp (Abderrahim et al., 2015; Sumczynski et al., 2016). In addition, the content of some phenolic compounds may vary depending on genetic variability, environmental and growing conditions (e.g., altitude and fertilization) (RepoCarrasco-Valencia et al., 2010).

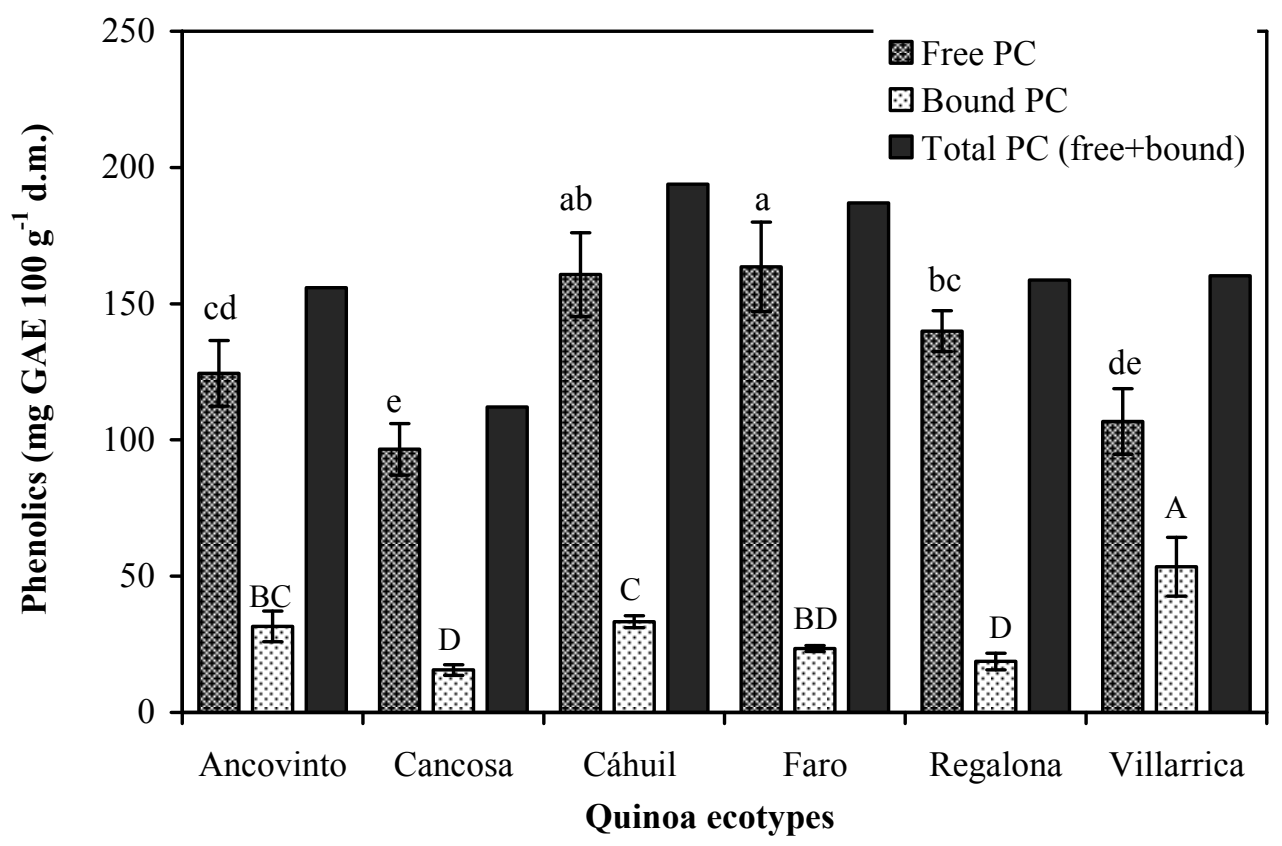

Fig. 1. Free phenolic compounds (Free PC), bound phenolic compounds (Bound PC) and total phenolic compounds (free + bound) of the six ecotypes of quinoa.

Values are expressed as mean \pm standard deviation $(n=3)$

Different letters above the bars indicate significant differences $(p<0.05)$ 


\section{Flavonoids and isoflavones of Chilean quinoa seeds}

The total flavonoid content (TFC) in quinoa seeds ranged from 109.4 to $211.1 \mathrm{mg}$ Catechin Equivalents (CAE) $100 \mathrm{~g}^{-1}$ (Fig. 2). Values of TFC varied depending on the production site. The lowest TFC was assayed in Regalona (109.4 mg CAE $100 \mathrm{~g}^{-1}$ ), whereas the highest TFC level was observed in Cancosa (211.1 mg CAE $\left.100 \mathrm{~g}^{-1}\right)(\mathrm{P}$ $<0.05)$. According to Hemalatha et al. (2016), the TFC of white quinoa from India (whole grain, hulls, dehulled grain, milled grain and bran fractions) ranged from 109 to $235 \mathrm{mg}$ CAE $100 \mathrm{~g}^{-1}$. A study conducted by Tang et al. (2015) showed significant differences in the TFC values between black, red and white quinoa seeds from a Canadian market (150-500 mg CAE $100 \mathrm{~g} \mathrm{~g}^{-1}$ ), while another study conducted by Abderrahim et al. (2015) showed that the TFC for thirteen Peruvian colored quinoa seeds ranged between 47 and $255 \mathrm{mg}$ Quercetin Equivalents (QE) $100 \mathrm{~g}^{-1}$.

The TFC in Chilean quinoa obtained in the present study is similar to the values found in the literature. It is possible that different compounds of flavonoids (e.g. flavonols, flavones, flavanone, flavan-3-ol, isoflavone) in quinoa seeds have contributed to this result. Previous studies have described that quinoa seeds are an exceptionally rich source of flavonols, such as quercetin and kaempferol (Hirose et al., 2010; RepoCarrasco-Valencia et al., 2010; Tang et al., 2015; Hemalatha et al., 2016), as well as of isoflavones, particularly daidzein and genistein (Lutz et al., 2013; Hemalatha et al., 2016). Isoflavone values in the tested quinoa seeds ranged from 0.60 to

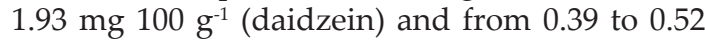
mg $100 \mathrm{~g}^{-1}$ (genistein) (Fig. 3). The contents of both isoflavones varied significantly between the samples $(\mathrm{p}<0.05)$, while daidzein was higher in all the ecotypes. This is in agreement with previous results reported by Lutz et al. (2013), who found that the content of daidzein was higher than that of genistein (daidzein: $0.70-1.15$ and genistein: $0.05-0.25 \mathrm{mg}^{\left.100 \mathrm{~g}^{-1}\right)}$ in three Chilean quinoa ecotypes (R49, UdeC9 and BO78), while Hemalatha et al. (2016) reported that the daidzein concentration ranged from 0.01 to $0.22 \mathrm{mg} 100 \mathrm{~g}^{-1}$ in a quinoa whole grain and its milled fractions.

Our results are in agreement with those of previous studies. It is important to note that differences in the concentrations of isoflavones in quinoa may be affected by a number of factors, such as genetical differences, growing environment (climate, soil type, sunlight) and other conditions (processing, concentration of proteins, postharvest conditions), which in turn could affect both content and antioxidant activity of these bioactive compounds (Lutz et al., 2013).

\section{Antioxidant capacity of Chilean quinoa seeds}

The antioxidant activity of the quinoa seeds was evaluated using two common chemical model systems, such as the DPPH and ORAC assays (Fig. 4). Levels of DPPH radical

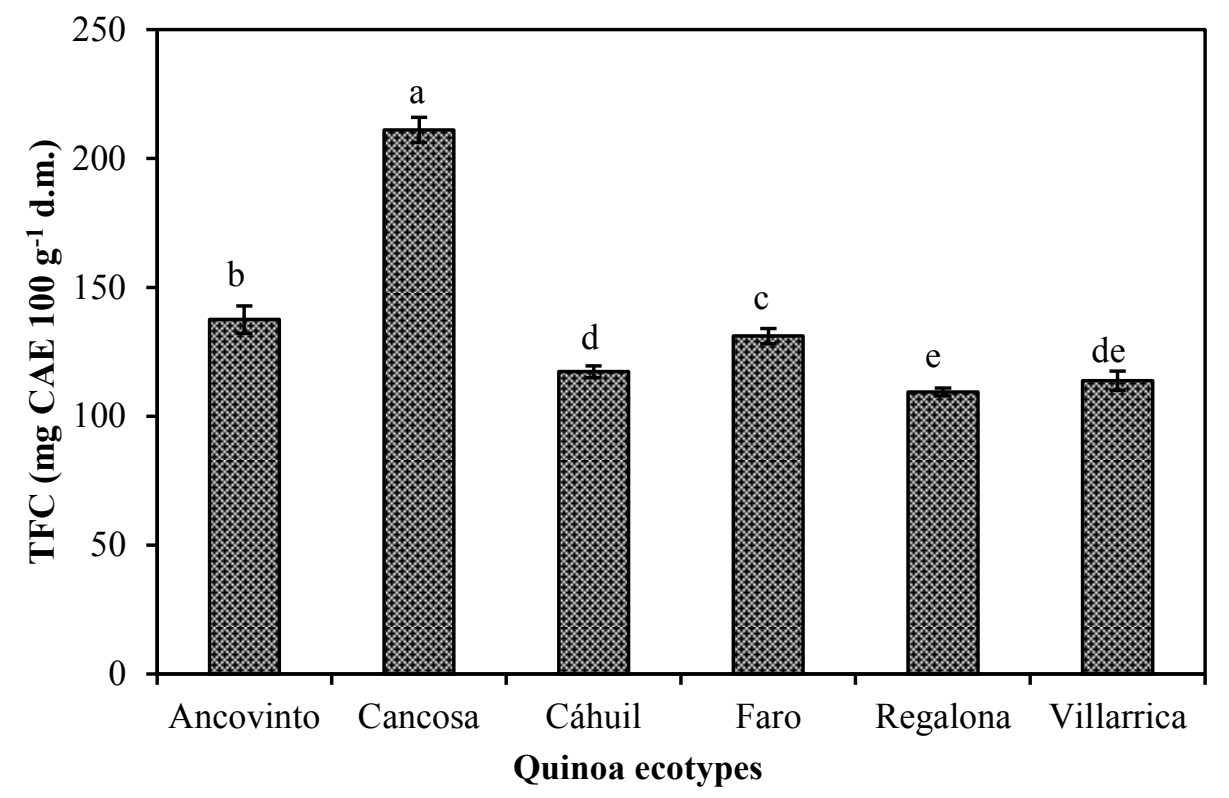

Fig. 2. Total flavonoid content (TFC) of the six quinoa ecotypes.

Value are expressed as mean \pm standard deviation $(n=3)$

Different letters above the bars indicate significant differences $(p<0.05)$ 


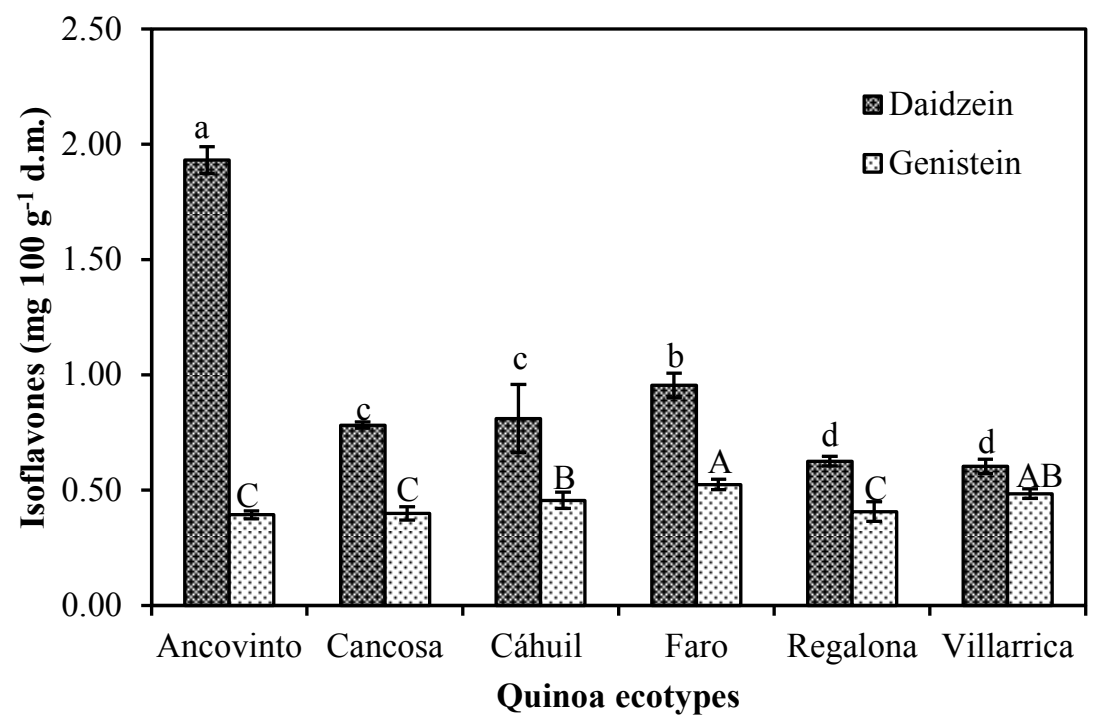

Fig. 3. Isoflavone (daidzein and genistein) content of the six quinoa ecotypes.

Value are expressed as mean \pm standard deviation $(n=3)$

Different letters above the bars indicate significant differences $(\mathrm{p}<0.05)$

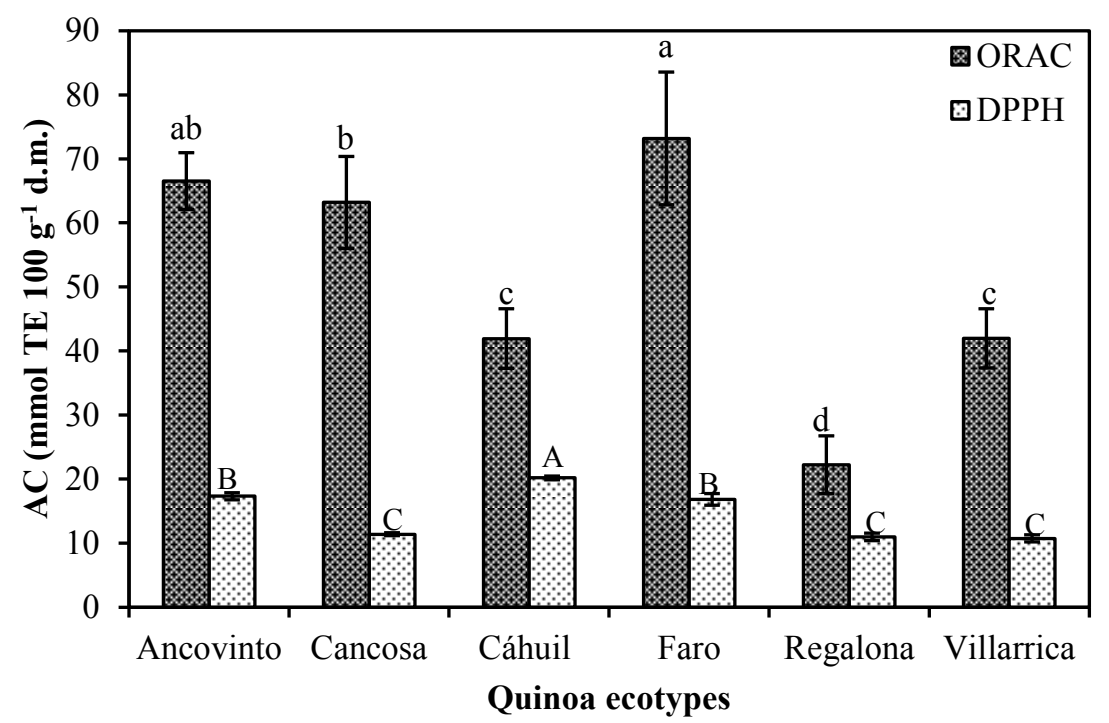

Fig. 4. Antioxidant capacity (AC) of the six quinoa ecotypes by means of 2,2,-diphenyl-2-picrylhydrazyl (DPPH) and Oxygen Radical Absorbance Capacity (ORAC) assays.

Value are expressed as mean \pm standard deviation $(n=3)$

Different letters above the bars indicate significant differences $(\mathrm{p}<0.05)$

scavenging activities ranged from 10.74 to 20.17 mmol Trolox Equivalents (TE) $100 \mathrm{~g}^{-1}(\mathrm{P}<0.05)$. Cáhuil exhibited the highest antioxidant activity (20.17 mmol TE $100 \mathrm{~g}^{-1}$ ), followed by Ancovinto and Faro, with values of 17.32 and $16.81 \mathrm{mmol}$ TE $100 \mathrm{~g}^{-1}$, respectively. On the contrary, the lowest antioxidant activity was found in Regalona (10.99 mmol TE $100 \mathrm{~g}^{-1}$ ) and Villarrica (10.74 mmol TE $\left.100 \mathrm{~g}^{-1}\right)(\mathrm{P}>0.05)$. The results obtained by DPPH assay in our quinoa ecotypes were much higher than the ones found by Hirose et al. (2010) and Tang et al. (2015) in quinoa seeds cultivated in Japan, South America and Ontario (Canada).

Different antioxidant activity assessments are required to take into account various mechanisms of action. In this sense, the ORAC values varied 
from 22.25 to $73.16 \mathrm{mmol} \mathrm{TE} 100 \mathrm{~g}^{-1}(\mathrm{P}<0.05)$. The highest level of antioxidant activity was obtained in Faro (73.16 mmol TE $\left.100 \mathrm{~g} \mathrm{~g}^{-1}\right)$. Lower antioxidant activities were found in Regalona (22.25 mmol TE $\left.100 \mathrm{~g}^{-1}\right)$ and Cáhuil (41.91 mmol TE $\left.100 \mathrm{~g}^{-1}\right)(\mathrm{P}<$ 0.05). Differences in the antioxidant of the quinoa ecotypes under study could be explained by genotype and cropping conditions. In this sense, limited rainfall in northern Chile can result in an increase of antioxidant capacity in quinoa due to the production of reactive oxygen species as it requires amounts of antioxidants to compensate stress and promote tolerance (Fischer et al., 2013).

\section{Antimicrobial activity of Chilean quinoa seeds: microbiological assays against Saccharomyces cerevisiae and Listeria innocua}

A control sample and four quinoa samples coded as Quinoa 1, Quinoa 2, Quinoa 3 and Quinoa 4 were used to evaluate the effect of the tested protocol (full suspension or supernatant). The use of full suspension presented serious drawbacks due to the deposits generated by the non-soluble material. Nevertheless, the results indicated that Quinoa 1 and Quinoa 3 showed a similar behavior regardless of the protocol used (Fig. 5A). Both samples showed a decrease in the initial cell concentration of $S$. cerevisiae, which continued up to $48 \mathrm{~h}$ and $72 \mathrm{~h}$ for the full suspension and supernatant, respectively. After this period, both samples showed a regrowth of the organism under study. Processing methods significantly affected the response against $S$. cerevisiae of Quinoa 2 and Quinoa 4 (Fig. 5B). In this case, the full suspension (Quinoa 2) did not present antifungal activity against $S$. cerevisiae, showing a similar microbial count throughout the assay. However, the supernatant of this quinoa ecotype (Quinoa 4) presented better results, particularly in the first 48 hours, with a significant reduction in microbial counts. Quinoa samples coded as Quinoa 3, Quinoa 4, Quinoa 5, Quinoa 6, Quinoa 7 and Quinoa 8, plus a control were used to evaluate the effect of the ecotype on the antimicrobial activity. These samples showed a different behavior (Fig. 5C). Cancosa ecotype (Quinoa 5) had no antifungal activity, and was similar to the control. Ancovinto and Faro ecotypes (Quinoa 3 and Quinoa 7) produced a decrease in the counts of the microorganism under evaluation that extended $72 \mathrm{~h}$, with a regrowth after this period. In addition, Cáhuil and Villarrica (Quinoa 4 and Quinoa 8) also showed a decrease, but a regrowth occurred after 48 h. Regalona (Quinoa 6) showed the best performance among the evaluated quinoa ecotypes, with significant decreases in the counts and no regrowth during the period under study, obtaining counts of $S$. cerevisiae below $10 \mathrm{CFU} \mathrm{mL}^{-1}$ $(\log <1)$ in the evaluated period.

On the other hand, no antimicrobial activity was detected in any of the quinoa ecotypes under study (full suspension and supernatant) when the initial inoculum of L. innocua (Gram-positive)

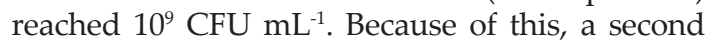
assay was performed using a lower initial cell

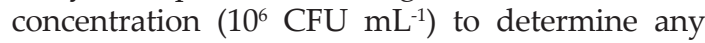
antibacterial activity against this strain. The results confirmed what was previously found, indicating that none of the samples have proven to be effective against L. innосиа. However, it can be observed that with a smaller inoculum, Regalona ecotype showed a slight decrease of the counts between 24 and $48 \mathrm{~h}$, reaching a value about $2 \log$ cycles lower than the control samples (Fig. 5D).

Even though antimicrobial properties of genistein and daidzein have been described in previous studies (Ulanowska et al., 2006), a high concentration of isoflavones could form aggregates that may decrease their antimicrobial efficacy (Dhayakaran et al., 2015). Moreover, Pompeu et al. (2015) obtained only inhibition to gram-negative bacteria using a lectin isolated from quinoa seeds. In general, the inhibition level is related to the chemical structure of the bioactive compounds and bacterial species (Landete, 2012). Nevertheless, these are preliminary analyses, and therefore further research is required to identify the antibacterial compounds from quinoa seeds and also determine their full spectrum of efficacy.

\section{CONCLUSIONS}

The results of this work allow concluding that the different ecotypes of Chilean quinoa studied can be considered as a good source of dietary fiber and other bioactive compounds, which contribute to the antioxidant capacity of the samples. With the exception of Cancosa, the rest of the ecotypes showed an averaged polyphenol content of $161.32 \pm 14.40 \mathrm{mg}$ GAE $100 \mathrm{~g}^{-1}$ d.m. $(p<0.05)$. The Northern and Central ecotypes exhibited the highest isoflavone concentrations. Cancosa was the ecotype that showed the highest flavonoid content (211.06 mg CAE $100 \mathrm{~g} \mathrm{~g}^{-1}$ d.m.). Faro, Ancovinto and Cancosa ecotypes presented the highest antioxidant capacity according to the ORAC method. Regarding antimicrobial activity, the Regalona ecotype showed the best performance against S. cerevisiae and L. innocua. This study contributes to the discussion on isoflavone content in quinoa seeds. It also demonstrates that beyond the recognized nutritional value quinoa has, its extracts possess an excellent potential as a source of bioactive compounds with antimicrobial and antioxidant activity, which may be used for the preservation of foods. 
A)

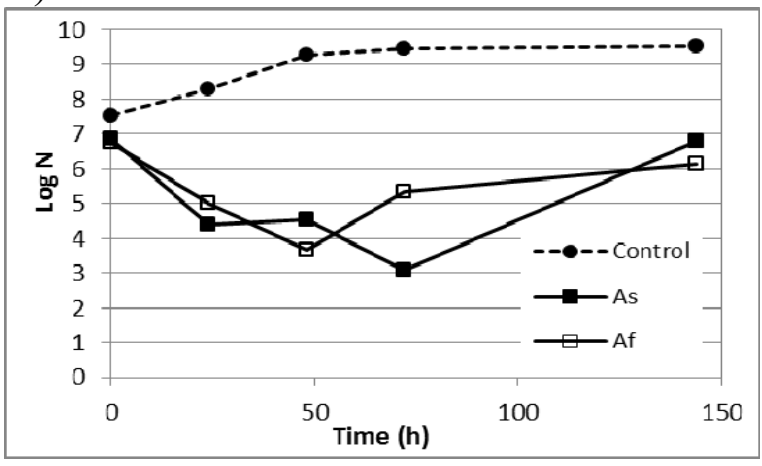

C)

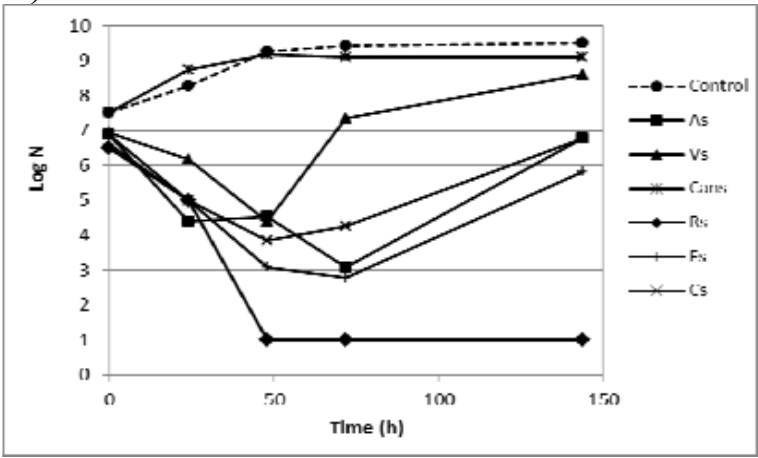

B)

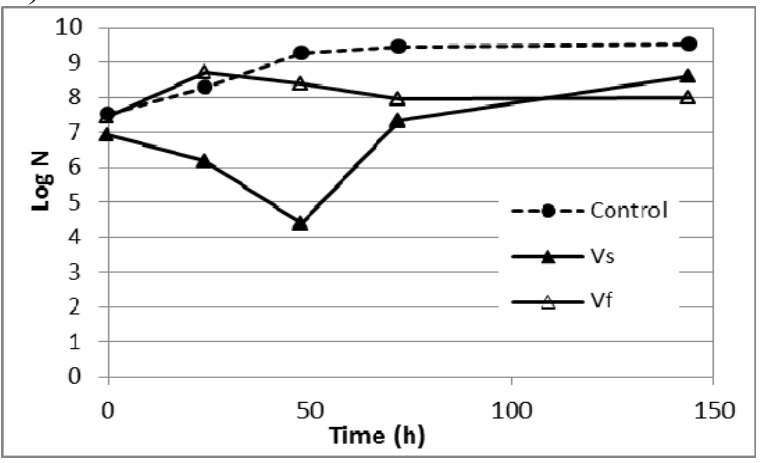

D)

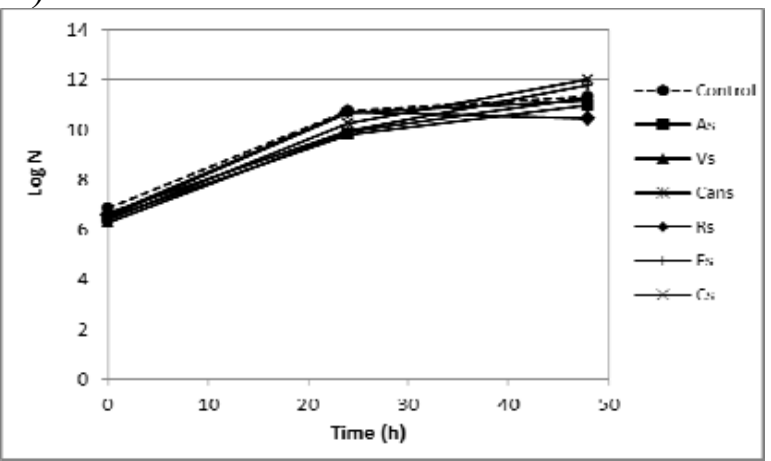

Fig. 5. Antimicrobial activity against Saccharomyces cerevisiae (A, B, C) and Listeria innocua (D). Control: Broth without quinoa; $\mathrm{A}_{f}$ : Full suspension of Ancovinto; $\mathrm{V}_{\mathrm{f}}$ : Full suspension of Villarrica; $\mathrm{A}_{s}$ :

Supernatant of Ancovinto; $\mathrm{V}_{\mathrm{s}}$ : Supernatant of Villarrica; $\mathrm{C}_{\mathrm{s}}$ : Supernatant of Cancosa; $\mathrm{R}_{\mathrm{s}}$ : Supernatant of Regalona; $\mathrm{F}_{\mathrm{s}}$ : Supernatant of Faro; $\mathrm{C}_{\mathrm{s}}$ : Supernatant of Cáhuil.

\section{ACKNOWLEDGEMENTS}

The authors gratefully acknowledge the financial support of project FONDECYT 1100638.

\section{LITERATURE CITED}

Abderrahim, F., E. Huanatico, R. Segura, S. Arribas, M.C. Gonzalez, and L. CondezoHoyos. 2015. Physical features, phenolic compounds, betalains and total antioxidant capacity of coloured quinoa seeds (Chenopodium quinoa Willd.) from Peruvian Altiplano. Food Chem. 183:83-90.

AOAC. 1990. Official Method of Analysis. Association of Official Analytical Chemists (AOAC). 15th ed. Washington DC, USA.

Chuah, A.M., Y.-C. Lee, T. Yamaguchi, H. Takamura, L.-J. Yin, and T. Matoba. 2008. Effect of cooking on the antioxidant properties of coloured peppers. Food Chem. 111:20-28.
Dhayakaran, R.P.A., S. Neethirajan, J. Xue, and J. Shi. 2015. Characterization of antimicrobial efficacy of soy isoflavones against pathogenic biofilms. LWT Food Sci. Technol. 63:859-865.

Dini, I., G. Carlo Tenore, and A. Dini. 2004. Phenolic constituents of Kancolla seeds. Food Chem. 84(2):163-168.

Fischer, S., R. Wilckens, J. Jara, and M. Aranda. 2013. Variation in antioxidant capacity of quinoa (Chenopodium quinoa Will) subjected to drought stress. Ind. Crops Prod. 46:341349.

Hemalatha, P., D.P. Bomzan, B.F. Sathyendra Rao, and Y.N. Sreerama. 2016. Distribution of phenolic antioxidants in whole and milled fractions of quinoa and their inhibitory effects on $\alpha$-amylase and $\alpha$-glucosidase activities. Food Chem. 199:330-338.

Hirose, Y., T. Fujita, T. Ishii, and N. Ueno. 2010. Antioxidative properties and flavonoid composition of Chenopodium quinoa seeds cultivated in Japan. Food Chem. 119:13001306. 
Huygens, D., P. Boeckx, P. Templer, L. Paulino, O. Van Cleemput, C. Oyarzún, et al. 2008. Mechanisms for retention of bioavailable nitrogen in volcanic rainforest soils. Nat. Geosci. 1:543-548.

Kim, D.O., O.K. Chun, Y.J. Kim, H.Y. Moon, and C.Y. Lee. 2003. Quantification of polyphenolics and their antioxidant capacity in fresh plums. J. Agric. Food Chem. 51:6509-6515.

Lamothe, L.M., S. Srichuwong, B.L. Reuhs, and B.R. Hamaker. 2015. Quinoa (Chenopodium quinoa W.) and amaranth (Amaranthus caudatus L.) provide dietary fibres high in pectic substances and xyloglucans. Food Chem. 167:490-496.

Landete, J.M. 2012. Updated knowledge about polyphenols: functions, bioavailability, metabolism, and health. Crit. Rev. Food Sci. Nutr. 52:936-948.

Lutz, M., A. Martínez, and E.A. Martínez. 2013. Daidzein and genistein contents in seeds of quinoa (Chenopodium quinoa Willd.) from local ecotypes grown in arid Chile. Ind. Crops Prod. 49:117-121.

Maradini Filho, A.M., M.R. Pirozi, J.T. Da Silva Borges, H.M. Pinheiro Sant'Ana, J.B. Paes Chaves, and J.S. Dos Reis Coimbra. 2015. Quinoa: nutritional, functional and antinutritional aspects. Crit. Rev. Food Sci. Nutr. 57:1618-1630.

Martínez, E.A., F.F. Fuentes, and D. Bazile. 2015. History of quinoa: its origin, domestication, diversification, and cultivation with particular reference to the Chilean context. p. 19-24. In Murphy, K., Matanguihan, J. (eds.). Quinoa: improvement and sustainable production. John Wiley \& Sons Inc., Hoboken, New Jersey, USA.

Miranda, M., J. Delatorre-Herrera, A. Vega-Gálvez, E. Jorquera, I. Quispe-Fuentes, and E.A. Martínez. 2014. Antimicrobial potential and phytochemical content of six diverse sources of quinoa seeds (Chenopodium quinoa Willd.). Agric. Sci. 5:1015-1024.

Miranda, M., A. Vega-Gálvez, J. López, G. Parada, M. Sanders, M. Aranda, et al. 2010. Impact of air drying temperature on nutritional properties, total phenolic content and antioxidant capacity of quinoa seeds (Chenopodium quinoa Willd.). Ind. Crops Prod. 32:258-263.

Navruz-Varli, S., and N. Sanlier, 2016. Nutritional and health benefits of quinoa (Chenopodium quinoa Willd.). J. Cereal Sci. 69:371-376.

Nowak, V., J. Du, and U.R. Charrondière, 2016. Assessment of the nutritional composition of quinoa (Chenopodium quinoa Willd.). Food Chem. 193:47-94.
Ou, B., D., Huang, M. Hampsch-Woodill, J. Flanagan, and E. Deemer, 2002. Analysis of antioxidant activities of common vegetables employing oxygen radical absorbance capacity (ORAC) and ferric reducing antioxidant power (FRAP) assays: a comparative study. J. Agric. Food Chem. 50:3122-3128.

Pompeu, D.G., M.A. Mattioli, R.I.M. de Azambuja Ribeiro, D.B. Gonçalves, J.T. de Magalhães, S. Marangoni, et al. 2015. Purification, partial characterization and antimicrobial activity of lectin from Chenopodium quinoa seeds. Food Sci. Technol. Campinas 35(4):696-703.

Repo-Carrasco-Valencia, R., J.K. Hellstr€om, J.M. Pihlava, and P.H. Mattila. 2010. Flavonoids and other phenolic compounds in Andean indigenous grains: quinoa (Chenopodium quinoa), kañiwa (Chenopodium pallidicaule) and kiwicha (Amaranthus caudatus). Food Chem. 120(1):128-133.

Repo-Carrasco-Valencia, R., and L. Serna. 2011. Quinoa (Chenopodium quinoa Willd.) as a source of dietary fiber and other functional components. Ciênc. Tecnol. Aliment. Campinas 31(1):225-230.

Sumczynski, D., E. Kotásková, H. Druzbíková, and J. Mlcek. 2016. Determination of contents and antioxidant activity of free and bound phenolics compounds and in vitro digestibility of commercial black and red rice (Oryza sativa L.) varieties. Food Chem. 211:339-346.

Tang, Y., X. Li, B. Zhang, P.X. Chen, R. Liu, and R. Tsao. 2015. Characterisation of phenolics, betanins and antioxidant activities in seeds of three Chenopodium quinoa Willd. genotypes. Food Chem. 166:380-388.

Ulanowska, K., A. Tkaczyk, G. Konopa, and G. Wegrzyn. 2006. Differential antibacterial activity of genistein arising from global inhibition of DNA, RNA and protein synthesis in some bacterial strains. Arch. Microbiol. 184:271-278.

Uribe, E., D. Marin, A. Vega-Galvez, I. QuispeFuentes, and A. Rodriguez. 2016. Assessment of vacuum-dried peppermint (Mentha piperita L.) as a source of natural antioxidants. Food Chem. 190:559-565.

Zhang, L., J. Li, S. Hogan, H. Chung, G.E. Welbaum, and K. Zhou. 2010. Inhibitory effect of raspberries on starch digestive enzyme and their antioxidant properties and phenolic composition. Food Chem. 119:592-599. 